\title{
Therapeutic Approaches to Delay the Onset of Alzheimer's Disease
}

\author{
Raj Kumar and Hani Atamna \\ Department of Basic Sciences, Neuroscience, The Commonwealth Medical College, Tobin Hall, 501 Madison Avenue, \\ Scranton, PA 18510, USA \\ Correspondence should be addressed to Hani Atamna, hatamna@tcmedc.org
}

Received 26 October 2010; Accepted 10 January 2011

Academic Editor: Christiaan Leeuwenburgh

Copyright (๑) 2011 R. Kumar and H. Atamna. This is an open access article distributed under the Creative Commons Attribution License, which permits unrestricted use, distribution, and reproduction in any medium, provided the original work is properly cited.

The key cytopathologies in the brains of Alzheimer's disease (AD) patients include mitochondrial dysfunction and energy hypometabolism, which are likely caused by the accumulation of small aggregates of amyloid- $\beta$ (A $\beta$ ) peptides. Thus, targeting these two abnormalities of the AD brain may hold promising therapeutic value for delaying the onset of AD. In his paper, we discuss two potential approaches to delay the onset of $\mathrm{AD}$. The first is the use of low dose of diaminophenothiazins (redox active agents) to prevent mitochondrial dysfunction and to attenuate energy hypometabolism. Diaminophenothiazines enhance mitochondrial metabolic activity and heme synthesis, both key factors in intermediary metabolism of the AD brain. The second is to use the naturally occurring osmolytes to prevent the formation of toxic forms of $A \beta$ and prevent oxidative stress. Scientific evidence suggests that both approaches may change course of the basic mechanism of neurodegeneration in AD. Osmolytes are brain metabolites which accumulate in tissues at relatively high concentrations following stress conditions. Osmolytes enhance thermodynamic stability of proteins by stabilizing natively-folded protein conformation, thus preventing aggregation without perturbing other cellular processes. Osmolytes may inhibit the formation of $\mathrm{A} \beta$ oligomers in vivo, thus preventing the formation of soluble oligomers. The potential significance of combining diaminophenothiazins and osmolytes to treat $\mathrm{AD}$ is discussed.

\section{Introduction}

1.1. An Overview of Alzheimer's Disease. Alzheimer's disease $(\mathrm{AD})$ is an irreversible brain disorder that slowly destroys memory and eventually a person's ability to perform the daily life tasks and activities. Memory problems are one of the first signs of $\mathrm{AD}$, and as it progresses, decline in other cognitive abilities such as poor judgment and mood changes starts to surface. Eventually people with severe AD cannot communicate and become completely dependent on others for their care. Most people with AD have lateonset of disease, which usually develops after age 60. However, a silent preclinical phase which precedes the development of AD clinical symptoms may span 2-8 years.

$\mathrm{AD}$ is a disease with a complex etiology and no single therapeutic approach is likely to prevent or lead to a cure. All current treatments focus on several different aspects, including management of behavioral symptoms or temporarily slowing the progress of the disease. However, none of these treatments changes or alter the inevitable course of the disease. Thus, even after almost three decades of research, $\mathrm{AD}$ is still dementia with a progressive failure to form new memories, and thereby interfering with the basic mechanism of the disease.

In recent years, it has been well-accepted that one of the pathological mechanisms of AD relates to the accumulation amyloid- $\beta(\mathrm{A} \beta)$ peptide in certain brain regions $[1] . \mathrm{A} \beta$ is a product of $\mathrm{A} \beta$ precursor protein $(\mathrm{A} \beta \mathrm{PP})$ via natural proteolytic processing. $\mathrm{A} \beta \mathrm{PP}$ is processed by three different proteases known as $\alpha-, \beta$-, and $\gamma$-secretase. Each of these three proteases cleaves $\mathrm{A} \beta \mathrm{PP}$ at different sites resulting in various $\mathrm{A} \beta$ species ranging from $39-43$ amino acid residues [2]. It has been shown that long species of $\mathrm{A} \beta\left(\mathrm{A} \beta_{42,43}\right)$ are strongly amyloidogenic and form aggregates readily compared to the short forms $\left(\mathrm{A} \beta_{39,40}\right) . \mathrm{A} \beta$ are the building blocks of insoluble extracellular $\mathrm{A} \beta$ deposits or senile plaques formation [3], a neuropathological hallmark of $\mathrm{AD}$ [3]. $\mathrm{AD}$ is also marked by neurofibrillary tangles, an intracellular filaments of highly 
phosphorylated tau protein. Impairment of cellular function in $\mathrm{AD}$ is demonstrated by a set of cytopathologies (reviewed in [4]) such as decline in cytochrome $c$ oxidase (complex IV), mitochondrial dysfunction, abnormal iron homeostasis, oxidative stress, dimerization of $\mathrm{A} \beta \mathrm{PP}$ and synaptic dysfunction [5-9], and energy hypometabolism. Several lines of evidence point towrads strong connection between small aggregates of $A \beta$ and mitochondrial dysfunction.

\subsection{Role of Amyloid- $\beta$ and Oligomers in Alzheimer's Disease.} According to the oldest so-called "cholinergic hypothesis", $\mathrm{AD}$ is caused by reduced levels of the neurotransmitter acetylcholine, which is important for memory. However, medications intended to treat acetylcholine deficiency have not been very effective in modifying the course of the disease. In the early 90s, the "amyloid hypothesis" was postulated according to which $\mathrm{A} \beta$ deposits arising from $\mathrm{A} \beta \mathrm{PP}$ cause $\mathrm{AD}$. As a result, specific proteases that process $A \beta P P$ were the focus of drug development as a possible mean to lower $A \beta$ production. However, several complications stem from the significance of these proteases for other biological functions creating serious obstacles in this front.

It is now well-accepted fact that $\mathrm{AD}$ is a neurodegenerative disorder associated with protein aggregation and misfolding of $\mathrm{A} \beta \mathrm{PP}$, which may be triggered by genetic polymorphism, age-dependent alteration to $\mathrm{A} \beta$ metabolism, or environmental factors that may promote accumulation and aggregation of $\mathrm{A} \beta$ peptide [10-13]. Thus, therapies directed at reversing $A \beta$ aggregation appeared promising. However, several limitations reduced the excitement in this approach as was the case for immunotherapy targeted using specific anti-A $\beta$ antibodies. Additionally, the lack of chemical safety of the available drugs to prevent $\mathrm{A} \beta$ aggregation was also a major concern.

There are reports showing a correlation between an early cognitive impairment in $\mathrm{AD}$ and increased oligomerization of $A \beta$, which precede the appearance of senile plaques [14-16]. Oligomers of $A \beta$ correlate with early cognitive impairment in $\mathrm{AD}[17,18]$. In recent years, studies using cells, mouse models, and human brain tissues strongly suggest that soluble $A \beta$ oligomers could be a toxic forms of $A \beta[19,20]$; however, experimental data for their direct in vivo toxicity is lacking [21]. Thus, preventive approaches may include also preventing the formation of $A \beta$ aggregates. However, it is not entirely clear which cellular compartment is the primary target of $A \beta$ toxicity. Interestingly, in addition to other extra- and intracellular compartments, $A \beta$ is also found in the mitochondria $[22,23]$, suggesting that neurotoxic effects of $\mathrm{A} \beta$ may be widespread [24], unlike earlier views that the extracellular senile plaques are the only main neurotoxic factor in AD. Energy hypometabolism and synaptic dysfunctions are proposed to be the primary target of $\mathrm{A} \beta$ neurotoxicity $[25,26]$. Thus, preventing mitochondrial dysfunction by identifying the primary metabolic pathway, specifically targeted by $\mathrm{A} \beta$ is a plausible approach to delay $\mathrm{AD}$ [27]. We propose that preventative approaches are more promising for lowering the prevalence of $\mathrm{AD}$. These approaches could target the formation of $\mathrm{A} \beta$ oligomers and enhance mitochondrial activity to counter energy deficiency in $\mathrm{AD}$.

\section{Role of Mitochondrial Dysfunction in Alzheimer's Disease}

Several lines of evidence suggest that impairment of mitochondrial function plays important role in the development of neurodegenerative diseases including AD. Mitochondrial dysfunction and impaired cellular energy is an early decline in metabolism seen in $\mathrm{AD}$ patients. In addition to the biochemical physiological changes, the brain mitochondria of $\mathrm{AD}$ patients exhibit substantial structural changes that included abnormal cristae, accumulation of osmophilic material, and smaller size compared to normal controls [23, 28]. It has been reported that mitochondrial fragmentation damages regions of nerve cell synapses. Excessive fragmentation of mitochondria causes synaptic injury leading to eventual nerve cell death. Since synapses are critical for learning and memory, their impairment leads to the dementia in $\mathrm{AD}$ patients. We have recently proposed that strong binding of $\mathrm{A} \beta$ with heme is a key factor associated with $A \beta$-mediated neurotoxicity $[29,30]$, which could be the primary metabolic pathway targeted by excess $\mathrm{A} \beta$ production [31-33], and thus interfering with mitochondrial structures and functions by increasing the production of nitric oxide (NO) leading to mitochondrial damage and impaired energy metabolism $[34,35]$. One of the key cytopathologies of $\mathrm{AD}$ include decline in cytochrome $\mathrm{c}$ oxidase (complex IV) and $\alpha \mathrm{KGDH}$, which seems to contribute to mitochondrial dysfunction [36-38]. This, abnormal biology of the mitochondria may contribute to energy deficiency in $\mathrm{AD}[35,39]$. There are reports showing an abnormal interaction of $\mathrm{A} \beta$ with key brain metabolites such as zinc, copper, cholesterol, mitochondrial protein import machinery, HrtA2 protease, ABAD, and heme $[22,31,40-$ 43]; however, their relation to cytopathologies of $\mathrm{AD}$ is not clear.

The decline in complex IV, which occurs in heme deficient cells, leads to similar structural consequences on mitochondria (unpublished observations). Several lines of experimental evidence provided support that heme metabolism may be a specific metabolic pathway that is targeted by $\mathrm{A} \beta$ peptides [43-46]. We showed recently a specific heme-binding motif in human $\mathrm{A} \beta$ peptides [27]. Based on our recent work and other laboratories, we propose that depletion of regulatory heme and the formation of $\mathrm{A} \beta$-heme peroxidase are key factors of mitochondrial dysfunction in the brains of AD patients. Due to phylogenic variation in the amino acid sequences of $A \beta$, differential heme-binding of $\mathrm{A} \beta$ could also explain why humans, but not rodents, develop AD-like neuropathology (Reviewed in [4]). Heme is responsible for the metabolic integrity of complex IV, which is a key factor in mitochondrial gene regulation systems; therefore, pathways that depend on heme may be properly regulated by lowering $\mathrm{A} \beta$ oligomeric forms, and enhanced heme synthesis may improve neuronal energy metabolism. 


\section{Therapeutic Approaches for Alzheimer's Disease and Challenges}

$\mathrm{AD}$ has a devastating impact on both personal and community levels. $\mathrm{AD}$ is the most common age-related dementia manifested by widespread progressive cognitive deterioration and impaired behavioral skills. With the aging US populations, and widespread prevalence of $\mathrm{AD}$ in these populations warrants immediate need for the management of this deleterious disease. In spite of efforts from scientific community for several decades, the available drug therapies for $\mathrm{AD}$ are only remedial without proper understanding of the underlying mechanisms involved therein. Unless new treatments are developed to decrease the likelihood of developing $\mathrm{AD}$, the number of individuals with this disease in the United States is expected to be more than 10 million in next three decades.

There is currently no specific cure for $\mathrm{AD}$ patients, but scientific research is unraveling the mysteries of $\mathrm{AD}$, including the causes and the mechanisms of the disease progression, which might one day effectively solve the Alzheimer's puzzle. In recent years, some understandings have already provided critical information about how to prevent, delay, or slow the nerve cell damage that leads to $\mathrm{AD}$, which may help maximize quality of life of these patients. However, drug treatments currently available are used to only manage the cognitive symptoms of $\mathrm{AD}$ by slowing the progression of symptoms for a while.

Despite the intensive research on $\mathrm{AD}$, a therapeutic or preventive strategy for $\mathrm{AD}$ remains elusive or limited at the most [47], which has been a key obstacle for the development of effective therapies for AD. The efficacy of currently available drugs has further been hampered by the fact that the effectiveness of these drugs progressively declines with the progression of disease. Thus, there is an urgent need for a new generation of drugs to prevent or delay the onset of $\mathrm{AD}$.

Except for imaging techniques, a precise and accurate diagnostic biomarker for $\mathrm{AD}$ is also lacking [48]. However, images results are excellent in following disease progress, but limited in revealing preclinical before protein deposits occur AD. The ultimate biomarker would preferably be a blood- or CSF-borne metabolite that indicates the risk for $\mathrm{AD}$ in advance of the clinical signs or protein deposits. $\mathrm{A} \beta$ heme peroxidase could serve a unique biomarker if found in blood or CSF of $\mathrm{AD}$ patients. $\mathrm{A} \beta$-heme has the advantage of being dependant on $\mathrm{A} \beta$ and it is tightly linked to a key brain metabolite (heme as mitochondrial metabolite), thus could indicate impairment in brain metabolism that depends on $\mathrm{A} \beta$ accumulation.

\section{Mitochondria As Targets for Delaying the Onset of Alzheimer's Disease}

Mitochondrial dysfunction in AD could serve as a therapeutic target an interest in developing mitochondrial drugs is emerging. Enhancing mitochondrial function and maintaining structural integrity of mitochondria could delay the onset of $\mathrm{AD}$. Below, we discuss pharmacological approaches to

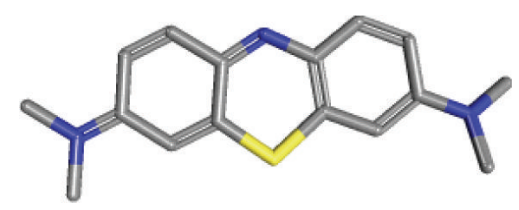

FIGURE 1: The chemical structure of methylene blue; a diaminophenothiazin.

enhance mitochondrial function and prevent the formation of $\mathrm{A} \beta$ toxic oligomers.

Mitochondria are a major energy source, and it has been known that energy deficiency can result in synaptic dysfunction and neurodegeneration of the hippocampus and cortical regions of the brain [49]. The brain is particularly sensitive to mitochondrial dysfunction, the resulting oxidative stress, and impaired energy metabolism [50-52]. Thus, improved energy metabolism through enhanced mitochondrial activity in the brain might be an effective approach to delay the onset of $\mathrm{AD}$.

Mitochondrial dysfunction in $\mathrm{AD}$ is associated with a decline in mitochondrial complex IV and energy deficiency. Due to involvement of mitochondria in cellular senescence and aging, it may contribute to neural dysfunction with age. Therefore, targeting mitochondria is an emerging field of research in finding therapeutic strategies to combat aging and neurodegenerative disorders. In fact, recent developments support this idea (reviewed in [53]), and potency of pharmacological agents to prevent or delay agerelated neurodegeneration is under investigation [54]. Our recent results with methylene blue (3,7 Bis-dimethylaminophenazathionium; MB) in countering some mitochondrial dysfunctions including mitochondrial complex IV formation, enhanced cellular oxygen consumption and heme synthesis, and reversed premature senescence are aimed at enhancing mitochondrial function, which could contribute to the antisenescence activity of $\mathrm{MB}$ [55-57]. Due to the ability of MB to cross the Blood Brain Barrier [58], our studies may provide a potential future therapeutic tool for $\mathrm{AD}$ and other related diseases using $\mathrm{MB}$.

$\mathrm{MB}$ is known as a redox indicator with a low redox potential, which allows it to cycle readily in mitochondria (Figure 1), and is easily soluble in both water and organic solvents, thus, $\mathrm{MB}$ and its derivative $\mathrm{MBH}_{2}$ can enter the mitochondria and other intracellular compartments such as lysosomes [59]. MB is the first chemical to induce mitochondrial respiratory complex, and we propose a new medical use for MB by increasing brain's reserve of both complex IV and the capacity to synthesize heme [56]. Increasing the activity of complex IV is intriguing as a decrease in complex IV activity causes cytotoxicity leading to increased oxidants production and decreased energy charge of the mitochondria [60-62]. MB in turn may elevate the levels of complex IV and improve mitochondrial function. Complex IV consumes more than $95 \%$ of the $\mathrm{O}_{2}$ that reaches cells, and thus, excess complex IV may play a key role in lowering the production of oxidants by decreasing the steady-state concentration of intracellular $\mathrm{O}_{2}$ in the mitochondria. Complex IV activity correlates well with the metabolic activity of cells and thus 
could improve cognitive performance. On the other hand, enhancing heme synthesis should help neural cells in delaying the onset of the consequences of sequestration of heme by huA $\beta$. Together, these findings suggest that MB may delay the onset of Alzheimer's dementia. Further, MB at higher concentrations ( $\mu \mathrm{M}$ range) are neurotoxic, and our findings show that $M B$ is effective in improving mitochondrial function at $\mathrm{nM}$ range of concentrations, which is consistent with the intrabrain concentration that can be achieved upon chronic treatment with $\mathrm{MB}$ [56]. MB has a long-standing, extensive history of medical uses [63] with an extended medical and safety record in humans, and its FDA approval for clinical trials in connotation to aging and age-related disorders may not be difficult to obtain on safety grounds.

\section{Mechanisms of Action of Methylene Blue and Its Clinical Applications}

In spite of widespread clinical uses of $\mathrm{MB}$ for decades, the mechanism(s) of its diverse biological actions are not clear. MB is readily absorbed by various organs including brain [64], and has a long history of clinical uses including chronic treatments of congenital methemoglobinemia, methemoglobinemia, psychiatric disorders, and more recently in the prevention of the side effects of ifosfamideinduced encepholopathy chemotherapy [65], and hypotension in septic shock [66-68]. MB has also been shown to protect against cyclosporine injury to kidney [69], streptozotocin injury to pancreas [70], ischemic-reperfusion injury [71], radiation [72], and enhances $\beta$-oxidation of long chain fatty acids [73]. Clinical doses of MB ranges between 1-

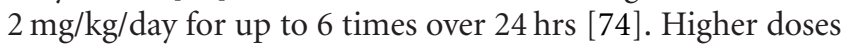
$(>7.5 \mathrm{mg} / \mathrm{Kg}$ ) of MB cause the formation of Heinz bodies in erythrocytes [75]. In addition, $\mathrm{MB}$ administration has been reported to improve the cognitive function in rats, and increase the activity of cytochrome c oxidase (complex IV) $[76,77]$ and decrease of monoamine oxidase activity in the brain, which may result in an increased dopamine concentration [78]. Some reports have proposed that MB may be acting by inhibiting the $\mathrm{NO}$-activating soluble guanylate cyclase [79], nitric oxide synthase [80], and MAO activity [78]. There are also reports suggesting that MB may be acting as an antioxidant precursor [81, 82]. However, in recent years, it has become quite clear that the biological effects of $\mathrm{MB}$ are not consistent with these mechanisms $[55,56,83]$. This discrepancy may in part be due to different doses of $\mathrm{MB}$ used in these experimental conditions, which have ranged from $>10 \mu \mathrm{M}$ to $<1 \mu \mathrm{M}$, suggesting that uses of $\mathrm{MB}$ at doses in the $\mathrm{nM}$ concentrations may follow a different mechanism $[55,56]$. For example the effect of $\mathrm{MB}$ on complex IV depends on the dose used [55]. Thus, interpretation of the experimental findings should take into consideration MB's dose especially when high (non-therapeutic) dose is used [84]. Based on our data and others, for the first time, we proposed a molecular mechanism explaining how MB might be affecting mitochondrial function [55-57]. We propose that diaminophenothiazins cycling between the reduced and the oxidized forms may explain, in part, their mitochondriaprotecting activity (Figure 1). This mechanism is proposed in
Figure 3 and in [55]. It is now an open secret that adequate assembly and activity of complex IV depends upon heme$a$ [85]; thus, the increased rate of heme synthesis with MB treatment could provide cells with heme to support the assembly of complex IV that could result in delaying mitochondrial dysfunction, cellular senescence, aging, and AD.

\section{Preventing Aggregation and Oligmerization of Amyloid- $\beta$ with Osmolytes}

Protein misfolding and/or instability leads to aggregate formation. Many neurodegenerative diseases exhibit deposits of aggregated proteins such as $\mathrm{A} \beta$ oligomers, senile plaques, phosphorylated tau (p-tau), $\alpha$-synuclein, and polyglutamine; and all are key neuropathologies in many CNS disorders. $A \beta$ oligomers in $\mathrm{AD}$ may progress to form large insoluble fibrils that form the plaques, a key hall mark of AD. Accumulation of these protein deposits exacerbate neurodegeneration due to the fact that the human brain has a limited capacity to prevent the formation or removal of these protein aggregates. It is known that limited protein degradation may contribute to the accumulation of these peptide deposits with age [86]. The aging brain also exhibits limited antioxidant activity and self-repair capacities (e.g., limited neurogenesis).

Our knowledge of the kinetics of the formation of protein aggregates in vivo in brain disorders as well as the limited understanding for the mechanism by which these aggregates interfere with neuronal metabolism function has impaired our capabilities for the development of preventative therapeutic strategies. In general, the intermediate species in the cascade of protein misfolding appear to be highly toxic and may interfere with basic metabolic activity of the brain. As for $A \beta$ oligomers it is not clear how toxic they would be in vivo [21]. However, removal or preventing the formation of such intermediate species may prove to be of great clinical value. We demonstrated that the binding of $\mathrm{A} \beta$ monomers and oligomers with heme results in sequestration of regulatory heme leading to impaired cellular metabolism. Therefore, preventative approaches to treating $\mathrm{AD}$ could be targeted at blocking the formation of $\mathrm{A} \beta$ oligomers, enhancing the synthesis of heme and complex IV, in addition to the use of antioxidants.

6.1. Oligmers as Targets for Delaying Alzheimer's Disease. Protein functions depends on maintaining and stabilizing their active conformation(s) under physiological and stress conditions [87]. Thus, under severe physical and chemical stress conditions, biological systems created mechanisms to maintain their functional conformations. These mechanisms are directed at preventing structural perturbations in proteins due to thermodynamic or chemical stressful conditions [88-91]. Biological systems that fail to provide proteins structure stabilizing conditions also fail to adapt to such conditions. As a result, often protein misfolding and aggregation occurs leading to a partial or complete loss of function, in addition to the formation of protein aggregates $[92,93]$. Both conditions have serious consequences on cell function and metabolism. 

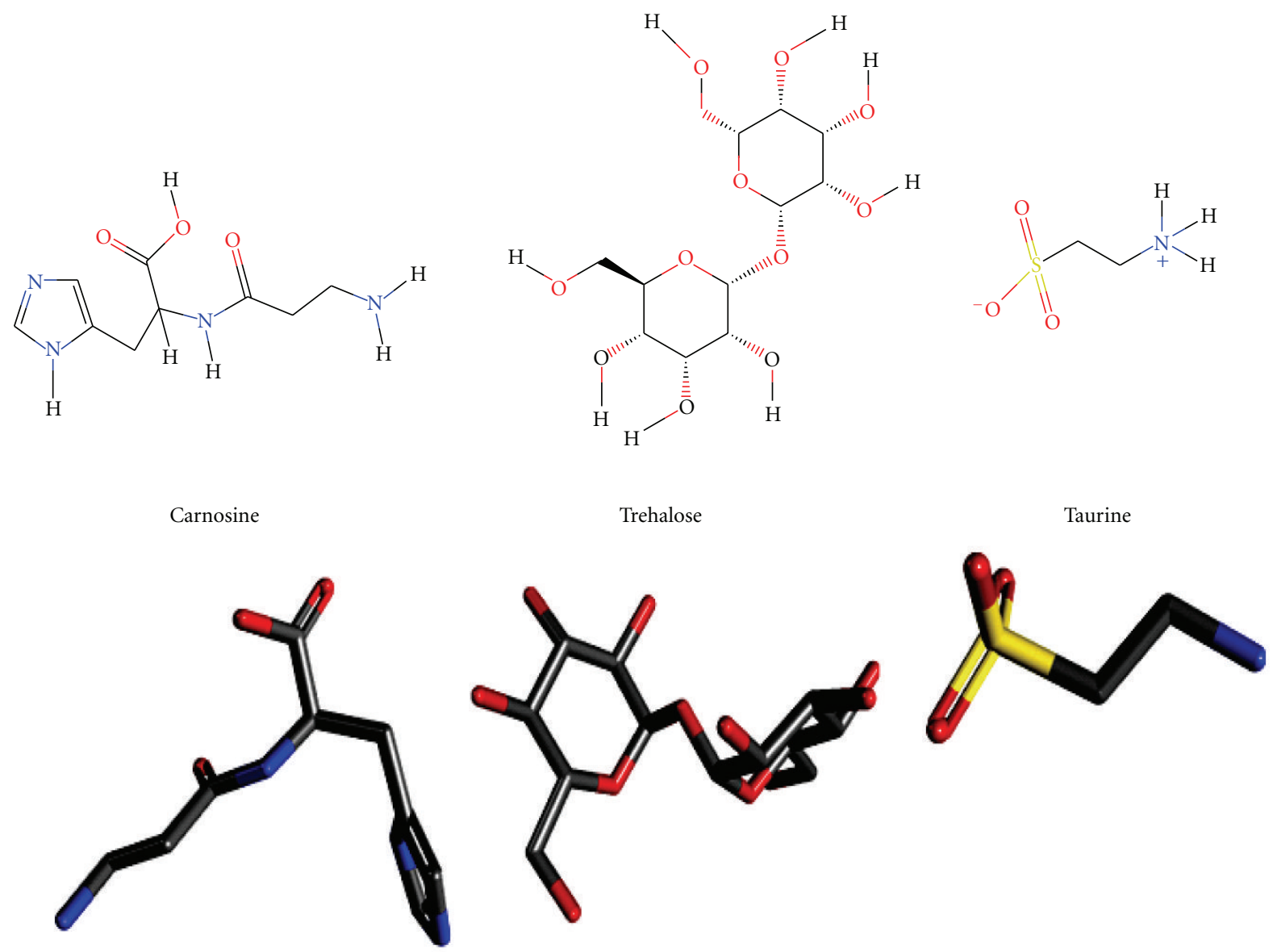

FIGURE 2: Chemical structure of selected osmolytes. Upper panel: structure in 2D; lower panel, structure in 3D configurations, respectively.

In order to adapt to stressful conditions, tissues created certain mechanisms such as degradation of misfolded proteins or accumulation of small organic solutes at high concentrations. These solutes can serve as antioxidants or play stabilizing role for intracellular structures of macromolecules. Osmolytes $[88,89,94]$ are group of endogenous chemicals produced by cells and accumulate to concentration as high as millimolars (Figure 2). The exact function of these metabolites and significance for intermediary metabolism and organ function is still under investigation. We are interested in finding scientific reasoning that links to identify the role of osmolytes and the high tissue connections. Experimental evidence points that osmolytes maintain stability and folding of proteins without perturbing other cellular processes, an action that requires relatively high intracellular concentrations [90, 91, 93, 95-97]. It is well known that following protein synthesis, a highly disordered unfolded state of the polypeptide chain passes through well-defined partially structured transition states before the fully folded protein forms. Molecular chaperones that deter aggregation of incompletely folded species also play role in correctly folding newly synthesized proteins [98]. If under certain conditions, the cellular environment becomes less than optimal for proper protein folding, then newly synthesized proteins become prone to aggregation [99-101]. Similarly, under these conditions, intermediates in protein processing pathways may also be subject to accumulation, misfolding, and aggregation (e.g., $\mathrm{A} \beta$ ). Protein aggregates, if not quickly removed, may transform to fibrils and other possible aggregates that accumulate in tissue and interfere with cell metabolism [102-107]. It is likely that small aggregates, as well as the highly organized fibrils and plaques, can give rise to pathological conditions, a common feature among many neurodegenerative diseases, including $\mathrm{AD}[97,108]$.

The biological significance of naturally occurring osmolytes has intrigued scientists for many years. There are a number of well-known naturally occurring osmolytes, which fall into three chemical classes: methylamines (trimethylamine-N-oxide, Choline-O-sulphate, and sarcosine), polyols (sorbitol, glycerol, sucrose and trehalose), and certain amino acids and their derivatives (glycine, taurine, proline and betaine) (Table 1). The role of osmolytes in protein folding, cell senescence, cell homeostasis, and mitochondrial structure has been described in various studies. However, more investigations are still needed to evaluate the role of osmolytes in health and diseases and their therapeutic potential.

Osmolytes interact with the peptide backbone and amino acid side-chains [109]. The potency of an osmolyte to promote protein folding and solubility is determined by the balance of these interactions and the solvophobic effects of the osmolyte. There are several studies to support the view 
TABLE 1: List of some known naturally occurring osmolytes in each class with their major presence in protecting the stability of specific proteins under harsh conditions.

\begin{tabular}{|c|c|c|}
\hline Type & Name(s) & Used by \\
\hline Polyols & $\begin{array}{l}\text { mannitol, glycerol, } \\
\text { sorbitol, inositol, pinitol }\end{array}$ & $\begin{array}{l}\text { plants, algae, } \\
\text { mammalian kidneys, } \\
\text { insects, reptiles, fish }\end{array}$ \\
\hline Amino Acid & $\begin{array}{l}\text { glycine, alanine, and } \\
\text { proline }\end{array}$ & mammalian cells \\
\hline $\begin{array}{l}\text { Amino Acids } \\
\text { Derivatives }\end{array}$ & $\begin{array}{l}\text { taurine, octopine, } \\
\text { alanine }\end{array}$ & $\begin{array}{l}\text { marine invertebrates, } \\
\text { prokaryotes }\end{array}$ \\
\hline Methylamines & $\begin{array}{l}\text { trimethylamine-N- } \\
\text { oxide, sarcosine, } \\
\text { phosphorylcholine, } \\
\text { glycine betaine }\end{array}$ & $\begin{array}{l}\text { marine invertebrates, } \\
\text { plants, mammalian } \\
\text { kidneys }\end{array}$ \\
\hline
\end{tabular}

that the powerful solvophobic effects of osmolytes on the peptide backbone dominate, such that the relative Gibbs free energy $(\Delta G)$ of the unfolded state is less favorable than that of the folded state ( $\Delta \mathrm{G}$ of the peptide folding is more negative).

The presence of several osmolytes inside cells raises questions about their role in protecting intracellular macromolecules under stressful conditions. The antioxidative activity of the osmolytes has been also proposed. Since the protection provided by an osmolyte does not depend on specific chemical interactions with the macromolecules, in principle, any of the osmolytes should be capable of replacing each other, depending upon either endogenous or exogenous availability of particular osmolyte(s) [110]. Since the role of protein backbone is critical in determining thermodynamic stability and folding of proteins in osmolyte solutions [111115], designing these small molecules (osmolytes) appears to be an excellent strategy and could be a critical step in preventing various critical proteins from misfolding or aggregation (6). This may have far-reaching consequences in understanding and preventing several deleterious diseases that are caused by protein misfolding/aggregation [116, 117]. Since organic osmolytes are naturally occurring molecules, they may have potential therapeutic applications without concerns of major toxic side effects [118].

Because of their capabilities to fold proteins into nativelike functional species, osmolytes have been the focus of several studies related to neurodegenerative diseases in which the pathogenesis is associated with the misfolding of specific proteins [119, 120]. These diseases include $\mathrm{AD}$, Huntington's disease (HD), and muscular dystrophy (MD). Trehalose, an osmoluyte, can significantly inhibit polyglutamine-mediated protein aggregation when orally administrated to the transgenic mouse model of Huntington's disease (a neurodegenerative disease) [114], and can increase the life span of Huntington's disease mouse model [114], indicating that trehalose is readily bioavailable. Osmolytes have similar effect of the folding of androgen receptor containing elongated polyglutamine chain length. Elongated polyglutamine chain in androgen receptor leads to formation of its aggregation and thus play role in causing neurodegeneration in Kennedy's disease [116].
Experimental finding suggests that $\mathrm{AD}$ toxicity could be linked to the formation of oligomeric forms of $\mathrm{A} \beta$ peptides and $\mathrm{AD}$ progression correlates with increasing aggregate formation of $\mathrm{A} \beta$. At physiological concentration, $\mathrm{A} \beta_{40}$ peptide incubated in the presence of trehalose inhibits aggregation of this peptide in a dose-dependent manner [121], and this osmolyte-mediated inhibition of $\mathrm{A} \beta_{40}$ peptide aggregation correlates with its toxic effects in neuronal cell system [121].

In these pathological conditions, specific misfolded aggregate-prone proteins are resistant to the normal cellular processes of protein folding and turnover and we propose that osmolytes may interfere with the production and/or the removal of these toxic intermediate aggregates. Further, these osmolytes can be attractive molecules for delaying the onset of neurodegenerative diseases characterized by protein misfolding and toxic aggregation. In particular, osmolytes may have therapeutic potential for treating AD, because of their effect on $\mathrm{A} \beta$ oligomers. Osmolytes may also help stabilize the senile plaques, preventing the shedding of $\mathrm{A} \beta$ oligomers. Osmolytes are also known to function as antioxidants $[122,123]$, and their level seems to decline in AD patients [124].

The research on naturally occurring osmolytes suggests that they have a protective role in promoting brain health, including resistance to neurodegeneration. Thus, there is potential for both prevention and treatment of neurodegenerative diseases using osmolytes $[125,126]$. The prospect of using natural osmolytes as a therapeutic tool for AD appears to be quite exciting and can have far reaching consequences in developing therapeutic tools for its prevention and/or management. However, while these proposals appear to be quite promising, more studies are needed to validate their effectiveness as a potential therapeutic target.

\section{Summary}

The mitochondrial role in health and disease has recently received immense scientific interest, particularly, because of the emerging field of mitochondria as a potential therapeutic target. Mitochondria play intricate role in energy, redox, and intermediary metabolism positioning them in cross road for health or disease. Genetic, environmental, and life style factors can lead to impairments in mitochondrial function. Impairment to mitochondrial function is found in numerous age-related degenerative diseases and disorders. Mitochondrial dysfunction leads to an increase in oxidative stress, energy hypometabolism, and impairs calcium homeostasis, ultimately leading to inadequate cellular function. Preventing mitochondrial dysfunction is presumed to have functional benefits, regardless of whether mitochondrial dysfunction is primary or secondary [57]. Thus, therapeutic strategies to improve mitochondrial function and delay the onset of age-related degenerative disorders are currently under investigation. We have shown that diaminophenothiazins (e.g., methylene blue, thionine, Figure 1) can delay cellular senescence by enhancing mitochondrial function, which are impaired in AD brains. 


\section{PM}

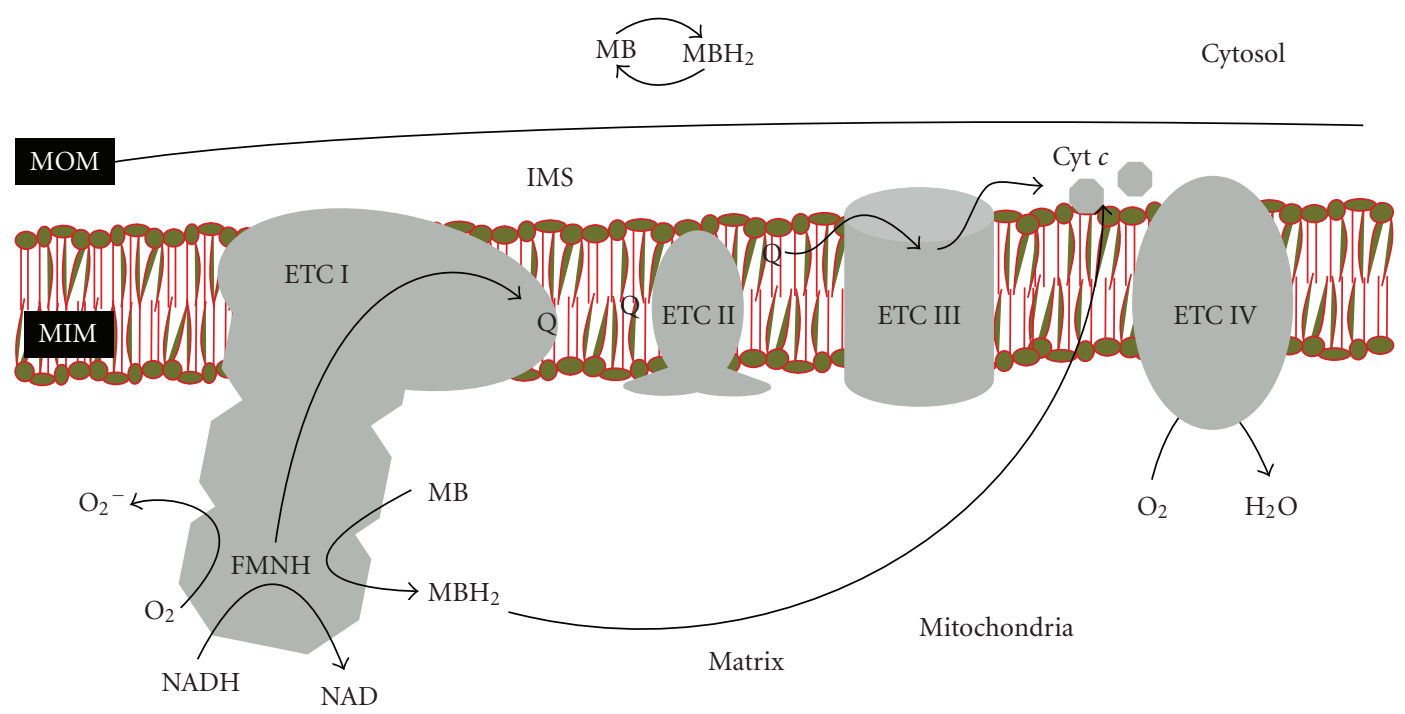

FIGURE 3: The proposed model for the interaction of methylene blue with specific mitochondrial and cellular components. ETC followed by roman number refers to the specific components of electron transport chain (ETC) of the mitochondria. MIM, MOM, and IMS refers to the mitochondrial inner membrane, mitochondrial outer membrane, and intermembrane space, respectively. $\mathrm{MB}_{\text {and }} \mathrm{MBH}_{2}$ refer to oxidized and reduced forms of methylene blue, respectively. The four complexes are: complex I (ETC I), complex II (ETC II), complex III (ETC III), and complex IV (ETC IV) in addition to ATP synthase (i.e., complex V). The electron transfer through each one of the ETC starts at ETC I, which catalyzes two electrons oxidation of NADH and continues until water is formed on ETC IV. Coenzyme Q serves as low-molecular weight electron carrier from ETCs I and II to III. Cytochrome $c$ (cyt $c$ ) serves as electron carrier from ETC III to ETC IV. Production of superoxide radical from complex I is proposed to be prevented by $\mathrm{MB}$, which serves as electron carrier that competes with molecular oxygen on the electrons "leaking" from complex I. During this process $\mathrm{MB}$ is converted to $\mathrm{MBH}_{2}$. Then $\mathrm{MBH}_{2}$, a reduce $\mathrm{MB}$, carries the electrons to cytochrome $c$, which is then oxidized by ETC IV [55].

Mounting evidence suggests a role of small aggregates of amyloid- $\beta(\mathrm{A} \beta)$ in the etiology of $\mathrm{AD}$. $\mathrm{A} \beta$ aggregates impair mitochondrial function, synaptic function, $\mathrm{Ca}^{++}$homeostasis and ultimately leading to cellular hypometabolism and neurdegeneration. A $\beta$ peptide can also be localized within the mitochondria of AD patients. Experimental evidence show that osmolytes can stabilize and enhance cellular proteins to adopt physiologically compatible conformation. Osmolytes are efficient antioxidants that may also increase neural resistance to oxidative stress caused by $\mathrm{A} \beta$. Thus, osmolytes may interfere with the aggregation of $A \beta$, enhance their proteolytic clearance, and counter oxidative stress [57].

We propose two different approaches to prevent or delay the onset of $\mathrm{AD}$. The first is directed at enhancing mitochondrial activity using $\mathrm{MB}$ to enhance mitochondrial function (Figure 3). Energy deficiency in AD may be contributed by impaired insulin (glucose) metabolism and mitochondrial function. Thus, concentrating on single impairment at the time would not be enough to resolve the energy hypometabolism in AD. Glucose metabolism depends on adequately functioning mitochondria and vice versa. Since both glucose and mitochondrial metabolism are interconnected, it might be more beneficial for $\mathrm{AD}$ patients to develop a therapeutic approach that resolves (or delay) both impairments. Successful merger of treatment with $\mathrm{MB}$ and intranasal delivery of insulin to the brain may prove valuable for $\mathrm{AD}$ patients. $\mathrm{MB}$ exerts its effect at very low $(\mathrm{nM})$ concentration, which in conjunction with its safety record in humans further minimizes any risk of side effects of chronic exposure to MB. The second approach is directed at preventing the aggregation of $\mathrm{A} \beta$ by using osmolytes, natural metabolites synthesized in the brain. Preventing the aggregation of $A \beta$ may enhance their proteolytic removal and decrease the risk of their interference with heme and mitochondrial metabolism. MB can also induce heme synthesis, thus, when combined with osmolytes, may assist in preventing heme deficiency. We propose $\mathrm{MB}$ and osmolytes could help delay the onset of $\mathrm{AD}$ by preventing $\mathrm{A} \beta$ oligomers formation, enhancing mitochondrial function, and attenuating heme deficiency.

We propose that preventative approaches for $\mathrm{AD}$ could be targeted at blocking the formation of $\mathrm{A} \beta$ oligomers, enhancing the synthesis of heme and complex IV, in addition to the use of antioxidants.

\section{Conflict of Interests}

Dr. Atamna has applied for patent on MB to treat mitochondrial dysfunction.

\section{Acknowledgments}

The study was supported in part by Ames Foundation, AFAR (H. Atamna), and NIH (R. Kumar). 


\section{References}

[1] C. Haass and D. J. Selkoe, "Soluble protein oligomers in neurodegeneration: lessons from the Alzheimer's amyloid $\beta$ peptide," Nature Reviews Molecular Cell Biology, vol. 8, no. 2, pp. 101-112, 2007.

[2] J. Nunan and D. H. Small, "Regulation of APP cleavage by $\alpha$-, $\beta$ - and $\gamma$-secretases," FEBS Letters, vol. 483, no. 1, pp. 6-10, 2000.

[3] C. S. Atwood, R. N. Martins, M. A. Smith, and G. Perry, "Senile plaque composition and posttranslational modification of amyloid- $\beta$ peptide and associated proteins," Peptides, vol. 23, no. 7, pp. 1343-1350, 2002.

[4] H. Atamna, "Heme binding to Amyloid- $\beta$ peptide: mechanistic role in Alzheimer's disease," Journal of Alzheimer's Disease, vol. 10, no. 2-3, pp. 255-266, 2006.

[5] W. D. Parker, C. M. Filley, and J. K. Parks, "Cytochrome oxidase deficiency in Alzheimer's disease," Neurology, vol. 40, no. 8, pp. 1302-1303, 1990.

[6] J. Valla, J. D. Berndt, and F. Gonzalez-Lima, "Energy hypometabolism in posterior cingulate cortex of Alzheimer's patients: superficial laminar cytochrome oxidase associated with disease duration," Journal of Neuroscience, vol. 21, no. 13, pp. 4923-4930, 2001.

[7] C. Daly, M. Sugimori, J. E. Moreira, E. B. Ziff, and R. Llinás, "Synaptophysin regulates clathrin-independent endocytosis of synaptic vesicles," Proceedings of the National Academy of Sciences of the United States of America, vol. 97, no. 11, pp. 6120-6125, 2000.

[8] W. R. Markesbery, "Oxidative stress hypothesis in Alzheimer's disease," Free Radical Biology and Medicine, vol. 23, no. 1, pp. 134-147, 1997.

[9] J. R. Connor, S. L. Menzies, S. M. Martin, and E. J. Mufson, "A histochemical study of iron, transferrin, and ferritin in Alzheimer's diseased brains," Journal of Neuroscience Research, vol. 31, no. 1, pp. 75-83, 1992.

[10] I. Blasko, R. Beer, M. Bigl et al., "Experimental traumatic brain injury in rats stimulates the expression, production and activity of Alzheimer's disease $\beta$-secretase (BACE-1)," Journal of Neural Transmission, vol. 111, no. 4, pp. 523-536, 2004.

[11] L. A. Farrer, L. A. Cupples, J. L. Haines et al., "Effects of age, sex, and ethnicity on the association between apolipoprotein E genotype and Alzheimer disease: a meta-analysis," Journal of the American Medical Association, vol. 278, no. 16, pp. 1349-1356, 1997.

[12] P. J. Landrigan, B. Sonawane, R. N. Butler, L. Trasande, R. Callan, and D. Droller, "Early environmental origins of neurodegenerative disease in later life," Environmental Health Perspectives, vol. 113, no. 9, pp. 1230-1233, 2005.

[13] G. S. Prasad, M. Wahlberg, V. Sridhar et al., "Crystal structures of transhydrogenase domain I with and without bound NADH," Biochemistry, vol. 41, no. 42, pp. 1274512754, 2002.

[14] T. Hartmann, S. C. Bieger, B. Brühl et al., "Distinct sites of intracellular production for Alzheimer's disease A $\beta 40 / 42$ amyloid peptides," Nature Medicine, vol. 3, no. 9, pp. 10161020, 1997.

[15] Y. Fezoui, D. M. Hartley, J. D. Harper et al., "An improved method of preparing the amyloid $\beta$-protein for fibrillogenesis and neurotoxicity experiments," Amyloid, vol. 7, no. 3, pp. 166-178, 2000.
[16] L. Mucke, E. Masliah, G. Q. Yu et al., "High-level neuronal expression of $\mathrm{A} \beta(1-42)$ in wild-type human amyloid protein precursor transgenic mice: synaptotoxicity without plaque formation," Journal of Neuroscience, vol. 20, no. 11, pp. 40504058, 2000.

[17] A. Kern and C. Behl, "The unsolved relationship of brain aging and late-onset Alzheimer disease," Biochimica et Biophysica Acta, vol. 1790, no. 10, pp. 1124-1132, 2009.

[18] L. M. Bierer, P. R. Hof, D. P. Purohit et al., "Neocortical neurofibrillary tangles correlate with dementia severity in Alzheimer's disease," Archives of Neurology, vol. 52, no. 1, pp. 81-88, 1995.

[19] G. Aliev, D. Seyidova, B. T. Lamb et al., "Mitochondria and vascular lesions as a central target for the development of Alzheimer's disease and Alzheimer disease-like pathology in transgenic mice," Neurological Research, vol. 25, no. 6, pp. 665-674, 2003.

[20] Y. Gong, L. Chang, K. L. Viola et al., "Alzheimer's diseaseaffected brain: presence of oligomeric $\mathrm{A} \beta$ ligands (ADDLs) suggests a molecular basis for reversible memory loss," Proceedings of the National Academy of Sciences of the United States of America, vol. 100, no. 18, pp. 10417-10422, 2003.

[21] R. J. Castellani, H. G. Lee, X. Zhu, G. Perry, and M. A. Smith, "Alzheimer disease pathology as a host response," Journal of Neuropathology and Experimental Neurology, vol. 67, no. 6, pp. 523-531, 2008.

[22] L. Devi, B. M. Prabhu, D. F. Galati, N. G. Avadhani, and H. K. Anandatheerthavarada, "Accumulation of amyloid precursor protein in the mitochondrial import channels of human Alzheimer's disease brain is associated with mitochondrial dysfunction," Journal of Neuroscience, vol. 26, no. 35, pp. 9057-9068, 2006.

[23] S. J. Baloyannis, "Mitochondrial alterations in Alzheimer's disease," Journal of Alzheimer's Disease, vol. 9, no. 2, pp. 119126, 2006.

[24] T. E. Golde and C. Janus, "Homing in on intracellular A $\beta$ ?" Neuron, vol. 45, no. 5, pp. 639-642, 2005.

[25] D. M. Walsh, I. Klyubin, J. V. Fadeeva et al., "Naturally secreted oligomers of amyloid $\beta$ protein potently inhibit hippocampal long-term potentiation in vivo," Nature, vol. 416, no. 6880, pp. 535-539, 2002.

[26] M. P. Lambert, A. K. Barlow, B. A. Chromy et al., "Diffusible, nonfibrillar ligands derived from $\mathrm{A} \beta$ are potent central nervous system neurotoxins," Proceedings of the National Academy of Sciences of the United States of America, vol. 95, no. 11, pp. 6448-6453, 1998.

[27] H. Atamna, "Amino acids variations in Amyloid- $\beta$ peptides, mitochondrial dysfunction, and new therapies for Alzheimer's disease," Journal of Bioenergetics and Biomembranes, vol. 41, no. 5, pp. 457-464, 2009.

[28] B. Su, X. Wang, D. Bonda, G. Perry, M. Smith, and X. Zhu, "Abnormal mitochondrial dynamics-a novel therapeutic target for Alzheimer's disease?” Molecular Neurobiology, vol. 41, no. 2-3, pp. 87-96, 2010.

[29] H. Atamna, "Heme, iron, and the mitochondrial decay of ageing," Ageing Research Reviews, vol. 3, no. 3, pp. 303-318, 2004.

[30] H. Atamna, D. W. Killilea, A. N. Killilea, and B. N. Ames, "Heme deficiency may be a factor in the mitochondrial and neuronal decay of aging," Proceedings of the National Academy of Sciences of the United States of America, vol. 99, no. 23, pp. 14807-14812, 2002. 
[31] J. W. Lustbader, M. Cirilli, C. Lin et al., "ABAD directly links A $\beta$ to mitochondrial toxicity in Alzheimer's disease," Science, vol. 304, no. 5669, pp. 448-452, 2004.

[32] H. Yamaguchi, T. Yamazaki, K. Ishiguro, M. Shoji, Y. Nakazato, and S. Hirai, "Ultrastructural localization of Alzheimer amyloid $\beta / \mathrm{A} 4$ protein precursor in the cytoplasm of neurons and senile plaque-associated astrocytes," Acta Neuropathologica, vol. 85, no. 1, pp. 15-22, 1992.

[33] P. J. Crouch, R. Blake, J. A. Duce et al., "Copper-dependent inhibition of human cytochrome $\mathrm{c}$ oxidase by a dimeric conformer of amyloid- $\beta$," Journal of Neuroscience, vol. 25, no. 3, pp. 672-679, 2005.

[34] D. H. Cho, T. Nakamura, J. Fang et al., " $\beta$-amyloid-related mitochondrial fission and neuronal injury," Science, vol. 324, no. 5923, pp. 102-105, 2009.

[35] X. Wang, B. Su, S. L. Siedlak et al., "Amyloid- $\beta$ overproduction causes abnormal mitochondrial dynamics via differential modulation of mitochondrial fission/fusion proteins," Proceedings of the National Academy of Sciences of the United States of America, vol. 105, no. 49, pp. 19318-19323, 2008.

[36] M. Fu, X. Zhu, J. Zhang et al., "Egr-1 target genes in human endothelial cells identified by microarray analysis," Gene, vol. 315, no. 1-2, pp. 33-41, 2003.

[37] R. S. Sohal, "Aging, cytochrome oxidase activity, and hydrogen peroxide release by mitochondria," Free Radical Biology and Medicine, vol. 14, no. 6, pp. 583-588, 1993.

[38] A. Boveris and B. Chance, "The mitochondrial generation of hydrogen peroxide. General properties and effect of hyperbaric oxygen," Biochemical Journal, vol. 134, no. 3, pp. 707-716, 1973.

[39] H. Du, L. Guo, F. Fang et al., "Cyclophilin D deficiency attenuates mitochondrial and neuronal perturbation and ameliorates learning and memory in Alzheimer's disease," Nature Medicine, vol. 14, no. 10, pp. 1097-1105, 2008.

[40] M. A. Lovell, J. D. Robertson, W. J. Teesdale, J. L. Campbell, and W. R. Markesbery, "Copper, iron and zinc in Alzheimer's disease senile plaques," Journal of the Neurological Sciences, vol. 158, no. 1, pp. 47-52, 1998.

[41] N. A. Avdulov, S. V. Chochina, U. Igbavboa, C. S. Warden, A. V. Vassiliev, and W. G. Wood, "Lipid binding to amyloid $\beta$-peptide aggregates: preferential binding of cholesterol as compared with phosphatidylcholine and fatty acids," Journal of Neurochemistry, vol. 69, no. 4, pp. 1746-1752, 1997.

[42] G. Bartzokis, T. A. Tishler, P. H. Lu et al., "Brain ferritin iron may influence age- and gender-related risks of neurodegeneration," Neurobiology of Aging, vol. 28, no. 3, pp. 414-423, 2007.

[43] H. Atamna, W. H. Frey, and N. Ko, "Human and rodent amyloid- $\beta$ peptides differentially bind heme: relevance to the human susceptibility to Alzheimer's disease," Archives of Biochemistry and Biophysics, vol. 487, no. 1, pp. 59-65, 2009.

[44] K. M. Cullen, Z. Kócsi, and J. Stone, "Microvascular pathology in the aging human brain: evidence that senile plaques are sites of microhaemorrhages," Neurobiology of Aging, vol. 27, no. 12, pp. 1786-1796, 2006.

[45] L. B. Gatta, M. Vitali, R. Verardi, P. Arosio, and D. Finazzi, "Inhibition of heme synthesis alters Amyloid Precursor Protein processing," Journal of Neural Transmission, vol. 116, no. 1, pp. 79-88, 2009.

[46] R. T. Perry, D. A. Gearhart, H. W. Wiener et al., "Hemoglobin binding to $A \beta$ and HBG2 SNP association suggest a role in Alzheimer's disease," Neurobiology of Aging, vol. 29, no. 2, pp. 185-193, 2008.
[47] B. J. Kelley and D. S. Knopman, "Alternative medicine and Alzheimer disease," Neurologist, vol. 14, no. 5, pp. 299-306, 2008.

[48] D. C. Bellinger, F. Trachtenberg, L. Barregard et al., "Neuropsychological and renal effects of dental amalgam in children: a randomized clinical trial," Journal of the American Medical Association, vol. 295, no. 15, pp. 1775-1783, 2006.

[49] M. F. Beal, "Energetics in the pathogenesis of neurodegenerative diseases," Trends in Neurosciences, vol. 23, no. 7, pp. 298-304, 2000.

[50] M. F. Beal, "Oxidative damage as an early marker of Alzheimer's disease and mild cognitive impairment," Neurobiology of Aging, vol. 26, no. 5, pp. 585-586, 2005.

[51] D. A. Butterfield, "Amyloid $\beta$-peptide (1-42)-induced oxidative stress and neurotoxicity: implications for neurodegeneration in Alzheimer's disease brain. A review," Free Radical Research, vol. 36, no. 12, pp. 1307-1313, 2002.

[52] K. Hirai, G. Aliev, A. Nunomura et al., "Mitochondrial abnormalities in Alzheimer's disease," Journal of Neuroscience, vol. 21, no. 9, pp. 3017-3023, 2001.

[53] G. Wagner, "Towards a life prolonging pill? Small molecules with anti-ageing properties," Current Drug Targets, vol. 7, no. 11, pp. 1531-1537, 2006.

[54] R. A. Miller, D. E. Harrison, C. M. Astle et al., "An aging interventions testing program: study design and interim report," Aging Cell, vol. 6, no. 4, pp. 565-575, 2007.

[55] H. Atamna, A. Nguyen, C. Schultz et al., "Methylene blue delays cellular senescence and enhances key mitochondrial biochemical pathways," FASEB Journal, vol. 22, no. 3, pp. 703-712, 2008.

[56] H. Atamna and A. Gharib, Methylene Blue Induces Mitochondrial Complex IV and Improves Cognitive Function and Grip Strength in Old Mice, Nova Science, Huntington, NY, USA, 2010.

[57] H. Atamna and R. Kumar, "Protective role of methylene blue in Alzheimer's disease via mitochondria and cytochrome c oxidase," Journal of Alzheimer's Disease, vol. 20, supplement 2, pp. S439-S452, 2010.

[58] C. Peter, D. Hongwan, A. Küpfer, and B. H. Lauterburg, "Pharmacokinetics and organ distribution of intravenous and oral methylene blue," European Journal of Clinical Pharmacology, vol. 56, no. 3, pp. 247-250, 2000.

[59] K. J. Mellish, R. D. Cox, D. I. Vernon, J. Griffiths, and S. B. Brown, "In vitro photodynamic activity of a series of methylene blue analogues," Photochemistry and Photobiology, vol. 75, no. 4, pp. 392-397, 2002.

[60] E. A. Shoubridge, "Cytochrome c oxidase deficiency," American Journal of Medical Genetics, vol. 106, pp. 46-52, 2001.

[61] Y. Kushnareva, A. N. Murphy, and A. Andreyev, "Complex I-mediated reactive oxygen species generation: modulation by cytochrome c and $\mathrm{NAD}(\mathrm{P})+$ oxidation-reduction state," Biochemical Journal, vol. 368, no. 2, pp. 545-553, 2002.

[62] M. H. Barros, B. Bandy, E. B. Tahara, and A. J. Kowaltowski, "Higher respiratory activity decreases mitochondrial reactive oxygen release and increases life span in Saccharomyces cerevisiae," Journal of Biological Chemistry, vol. 279, no. 48, pp. 49883-49888, 2004.

[63] J. C. V. P. Moura and N. Cordeiro, "3,7-bis(dialkylamino)phenothiazin-5-ium derivatives: biomedical applications and biological activity," Current Drug Targets, vol. 4, no. 2, pp. 133-141, 2003. 
[64] J. Rengelshausen, J. Burhenne, M. Fröhlich et al., "Pharmacokinetic interaction of chloroquine and methylene blue combination against malaria," European Journal of Clinical Pharmacology, vol. 60, no. 10, pp. 709-715, 2004.

[65] P. N. Patel, "Methylene blue for management of ifosfamideinduced encephalopathy," Annals of Pharmacotherapy, vol. 40, no. 2, pp. 299-303, 2006.

[66] D. P. Betten, R. B. Vohra, M. D. Cook, M. J. Matteucci, and R. F. Clark, "Antidote use in the critically ill poisoned patient," Journal of Intensive Care Medicine, vol. 21, no. 5, pp. 255-277, 2006.

[67] G. J. Naylor, B. Martin, S. E. Hopwood, and Y. Watson, "A two-year double-blind crossover trial of the prophylactic effect of methylene blue in manic-depressive psychosis," Biological Psychiatry, vol. 21, no. 10, pp. 915-920, 1986.

[68] R. W. De-Oliveira and F. S. Guimarães, "Anxiolytic effect of methylene blue microinjected into the dorsal periaqueductal gray matter," Brazilian Journal of Medical and Biological Research, vol. 32, no. 12, pp. 1529-1532, 1999.

[69] R. Rezzani, L. Rodella, G. Corsetti, and R. Bianchi, "Does methylene blue protect the kidney tissues from damage induced by ciclosporin A treatment?" Nephron, vol. 89, no. 3, pp. 329-336, 2001.

[70] M. Haluzik, J. Nedvídková, and J. Škrha, “Treatment with the NO-synthase inhibitor, methylene blue, moderates the decrease in serum leptin concentration in streptozotocininduced diabetes," Endocrine Research, vol. 25, no. 2, pp. 163$171,1999$.

[71] S. C. Salaris, C. F. Babbs, and W. D. Voorhees, "Methylene blue as an inhibitor of superoxide generation by xanthine oxidase. A potential new drug for the attenuation of ischemia/reperfusion injury," Biochemical Pharmacology, vol. 42, no. 3, pp. 499-506, 1991.

[72] B. A. Teicher, T. S. Herman, and M. E. Kaufmann, "Cytotoxicity, radiosensitization, and DNA interaction of platinum complexes of thiazin and xanthene dyes," Radiation Research, vol. 121, no. 2, pp. 187-195, 1990.

[73] T. M. Visarius, J. W. Stucki, and B. H. Lauterburg, "Inhibition and stimulation of long-chain fatty acid oxidation by chloroacetaldehyde and methylene blue in rats," Journal of Pharmacology and Experimental Therapeutics, vol. 289, no. 2, pp. 820-824, 1999.

[74] J. Clifton II and J. B. Leikin, "Methylene blue," American Journal of Therapeutics, vol. 10, no. 4, pp. 289-291, 2003.

[75] M. R. Sills and W. H. Zinkham, "Methylene blue-induced Heinz body hemolytic anemia," Archives of Pediatrics and Adolescent Medicine, vol. 148, no. 3, pp. 306-310, 1994.

[76] J. L. Martinez Jr., R. A. Jensen, B. J. Vasquez, T. McGuinness, and J. L. McGaugh, "Methylene blue alters retention of inhibitory avoidance responses," Physiological Psychology, vol. 6, no. 3, pp. 387-390, 1978.

[77] N. L. Callaway, P. D. Riha, A. K. Bruchey, Z. Munshi, and F. Gonzalez-Lima, "Methylene blue improves brain oxidative metabolism and memory retention in rats," Pharmacology Biochemistry and Behavior, vol. 77, no. 1, pp. 175-181, 2004.

[78] R. R. Ramsay, C. Dunford, and P. K. Gillman, "Methylene blue and serotonin toxicity: inhibition of monoamine oxidase A (MAO A) confirms a theoretical prediction," British Journal of Pharmacology, vol. 152, no. 6, pp. 946-951, 2007.

[79] E. A. Dierks and J. N. Burstyn, "The deactivation of soluble guanylyl cyclase by redox-active agents," Archives of Biochemistry and Biophysics, vol. 351, no. 1, pp. 1-7, 1998.
[80] B. Mayer, F. Brunner, and K. Schmidt, "Inhibition of nitric oxide synthesis by methylene blue," Biochemical Pharmacology, vol. 45, no. 2, pp. 367-374, 1993.

[81] P. E. Meissner, G. Mandi, S. Witte et al., "Safety of the methylene blue plus chloroquine combination in the treatment of uncomplicated falciparum malaria in young children of Burkina Faso [ISRCTN27290841]," Malaria Journal, vol. 4, Article ID 45, 2005.

[82] M. J. Kelner, R. Bagnell, B. Hale, and N. M. Alexander, "Methylene blue competes with paraquat for reduction by flavo-enzymes resulting in decreased superoxide production in the presence of heme proteins," Archives of Biochemistry and Biophysics, vol. 262, no. 2, pp. 422-426, 1988.

[83] N. Zacharakis, P. Tone, C. S. Flordellis, M. E. Maragoudakis, and N. E. Tsopanoglou, "Methylene blue inhibits angiogenesis in chick chorioallontoic membrane through a nitric oxide-independent mechanism," Journal of Cellular and Molecular Medicine, vol. 10, no. 2, pp. 493-498, 2006.

[84] D. X. Medina, A. Caccamo, and S. Oddo, "Methylene blue reduces $\mathrm{A} \beta$ levels and rescues early cognitive deficit by increasing proteasome activity," Brain Pathology, vol. 21, no. 2, pp. 140-149, 2011.

[85] H. S. Carr and D. R. Winge, "Assembly of cytochrome c oxidase within the mitochondrion," Accounts of Chemical Research, vol. 36, no. 5, pp. 309-316, 2003.

[86] G. R. Luo and W. D. Le, "Collective roles of molecular chaperones in protein degradation pathways associated with neurodegenerative diseases," Current Pharmaceutical Biotechnology, vol. 11, no. 2, pp. 180-187, 2010.

[87] P. W. Hochachka and G. N. Somero, Biochemical Adaptation. Mechanism and Process in Physiological Evolution, Oxford University Press, Oxford, UK, 2002.

[88] D. W. Bolen and I. V. Baskakov, "The osmophobic effect: natural selection of a thermodynamic force in protein folding," Journal of Molecular Biology, vol. 310, no. 5, pp. 955963, 2001.

[89] R. L. Baldwin and G. D. Rose, "Is protein folding hierarchic? I. Local structure and peptide folding," Trends in Biochemical Sciences, vol. 24, no. 1, pp. 26-33, 1999.

[90] M. B. Burg, "Molecular basis of osmotic regulation," American Journal of Physiology, vol. 268, no. 6, pp. F983-F996, 1995.

[91] C. Bai, J. Biwersi, A. S. Verkman, and M. A. Matthay, "A mouse model to test the in vivo efficacy of chemical chaperones," Journal of Pharmacological and Toxicological Methods, vol. 40, no. 1, pp. 39-45, 1998.

[92] C. N. Pace, "The stability of globular proteins," CRC Critical Reviews in Biochemistry, vol. 3, no. 1, pp. 1-43, 1975.

[93] P. H. Yancey, M. E. Clark, S. C. Hand, R. D. Bowlus, and G. N. Somero, "Living with water stress: evolution of osmolyte systems," Science, vol. 217, no. 4566, pp. 1214-1222, 1982.

[94] H. Atamna and H. Ginsburg, "Heme degradation in the presence of glutathione. A proposed mechanism to account for the high levels of non-heme iron found in the membranes of hemoglobinopathic red blood cells," Journal of Biological Chemistry, vol. 270, no. 42, pp. 24876-24883, 1995.

[95] C. C. Mello and D. Barrick, "Measuring the stability of partly folded proteins using TMAO," Protein Science, vol. 12, no. 7, pp. 1522-1529, 2003.

[96] P. H. Yancey, "Organic osmolytes as compatible, metabolic and counteracting cytoprotectants in high osmolarity and other stresses," Journal of Experimental Biology, vol. 208, no. 15, pp. 2819-2830, 2005. 
[97] I. Baskakov and D. W. Bolen, "Forcing thermodynamically unfolded proteins to fold," Journal of Biological Chemistry, vol. 273, no. 9, pp. 4831-4834, 1998.

[98] Q. J. Quinones, G. G. de Ridder, and S. V. Pizzo, "GRP78: a chaperone with diverse roles beyond the endoplasmic reticulum," Histology and Histopathology, vol. 23, no. 11, pp. 1409-1416, 2008.

[99] J. W. Kelly, "The alternative conformations of amyloidogenic proteins and their multi-step assembly pathways," Current Opinion in Structural Biology, vol. 8, no. 1, pp. 101-106, 1998.

[100] P. T. Lansbury Jr., "Evolution of amyloid: what normal protein folding may tell us about fibrillogenesis and disease," Proceedings of the National Academy of Sciences of the United States of America, vol. 96, no. 7, pp. 3342-3344, 1999.

[101] S. W. Davies, M. Turmaine, B. A. Cozens et al., "Formation of neuronal intranuclear inclusions underlies the neurological dysfunction in mice transgenic for the HD mutation," Cell, vol. 90, no. 3, pp. 537-548, 1997.

[102] J. M. Warrick, H. L. Paulson, G. L. Gray-Board et al., "Expanded polyglutamine protein forms nuclear inclusions and causes neural degeneration in Drosophila," Cell, vol. 93, no. 6, pp. 939-949, 1998.

[103] I. A. Klement, P. J. Skinner, M. D. Kaytor et al., "Ataxin-1 nuclear localization and aggregation: role in polyglutarnineinduced disease in SCA1 transgenic mice," Cell, vol. 95, no. 1, pp. 41-53, 1998.

[104] T. V. Strong, D. A. Tagle, J. M. Valdes et al., "Widespread expression of the human and rat Huntington's disease gene in brain and nonneural tissues," Nature Genetics, vol. 5, no. 3, pp. 259-265, 1993.

[105] W. R. Kennedy, M. Alter, and J. H. Sung, "Progressive proximal spinal and bulbar muscular atrophy of late onset. A sex-linked recessive trait," Neurology, vol. 18, no. 7, pp. 671680,1968

[106] A. R. La Spada, E. M. Wilson, D. B. Lubahn, A. E. Harding, and K. H. Fischbeck, "Androgen receptor gene mutations in X-linked spinal and bulbar muscular atrophy," Nature, vol. 352, no. 6330, pp. 77-79, 1991.

[107] The Huntington's Disease Collaborative Research Group, “A novel gene containing a trinucleotide repeat that is expanded and unstable on Huntington's disease chromosomes," Cell, vol. 72, no. 6, pp. 971-983, 1993.

[108] M. DiFiglia, E. Sapp, K. O. Chase et al., "Aggregation of huntingtin in neuronal intranuclear inclusions and dystrophic neurites in brain," Science, vol. 277, no. 5334, pp. 1990-1993, 1997.

[109] R. Kumar, "Role of naturally occurring osmolytes in protein folding and stability," Archives of Biochemistry and Biophysics, vol. 491, no. 1-2, pp. 1-6, 2009.

[110] B. Kempf and E. Bremer, "Uptake and synthesis of compatible solutes as microbial stress responses to high-osmolality environments," Archives of Microbiology, vol. 170, no. 5, pp. 319-330, 1998.

[111] T. Y. Lin and S. N. Timasheff, "Why do some organisms use a urea-methylamine mixture as osmolyte? Thermodynamic compensation of urea and trimethylamine $\mathrm{N}$-oxide interactions with protein," Biochemistry, vol. 33, no. 42, pp. 1269512701, 1994

[112] R. Singh, I. Haque, and F. Ahmad, "Counteracting osmolyte trimethylamine $\mathrm{N}$-oxide destabilizes proteins at $\mathrm{pH}$ below its $\mathrm{pK}$ : measurements of thermodynamic parameters of proteins in the presence and absence of trimethylamine N-oxide," Journal of Biological Chemistry, vol. 280, no. 12, pp. 1103511042, 2005.
[113] F. Anjum, V. Rishi, and F. Ahmad, "Compatibility of osmolytes with Gibbs energy of stabilization of proteins," Biochimica et Biophysica Acta, vol. 1476, no. 1, pp. 75-84, 2000.

[114] M. Tanaka, Y. Machida, S. Niu et al., "Trehalose alleviates polyglutamine-mediated pathology in a mouse model of Huntington disease," Nature Medicine, vol. 10, no. 2, pp. 148154, 2004.

[115] P. Davies, K. Watt, S. M. Kelly, C. Clark, N. C. Price, and I. J. McEwan, "Consequences of poly-glutamine repeat length for the conformation and folding of the androgen receptor amino-terminal domain," Journal of Molecular Endocrinology, vol. 41, no. 5-6, pp. 301-314, 2008.

[116] J. Duff, P. Davies, K. Watt, and I. J. McEwan, "Structural dynamics of the human androgen receptor: implications for prostate cancer and neurodegenerative disease," Biochemical Society Transactions, vol. 34, no. 6, pp. 1098-1102, 2006.

[117] R. A. Irvine, H. Ma, M. C. Yu, R. K. Ross, M. R. Stallcup, and G. A. Coetzee, "Inhibition of p160-mediated coactivation with increasing androgen receptor polyglutamine length," Human Molecular Genetics, vol. 9, no. 2, pp. 267-274, 2000.

[118] E. M. Becker, J. M. Greer, P. Ponka, and D. R. Richardson, "Erythroid differentiation and protoporphyrin IX downregulate frataxin expression in Friend cells: characterization of frataxin expression compared to molecules involved in iron metabolism and hemoglobinization," Blood, vol. 99, no. 10, pp. 3813-3822, 2002.

[119] D. M. Walsh, I. Klyubin, G. M. Shankar et al., "The role of cell-derived oligomers of $\mathrm{A} \beta$ in Alzheimer's disease and avenues for therapeutic intervention," Biochemical Society Transactions, vol. 33, no. 5, pp. 1087-1090, 2005.

[120] M. A. Singer and S. Lindquist, "Multiple effects of trehalose on protein folding in vitro and in vivo," Molecular Cell, vol. 1, no. 5, pp. 639-648, 1998.

[121] R. Liu, H. Barkhordarian, S. Emadi, B. P. Chan, and M. R. Sierks, "Trehalose differentially inhibits aggregation and neurotoxicity of beta-amyloid 40 and 42," Neurobiology of Disease, vol. 20, no. 1, pp. 74-81, 2005.

[122] V. P. Reddy, M. R. Garrett, G. Perry, and M. A. Smith, "Carnosine: a versatile antioxidant and antiglycating agent," Science of Aging Knowledge Environment, vol. 2005, no. 18, p. pe12, 2005.

[123] M. Mozdzan, J. Szemraj, J. Rysz, and D. Nowak, “Antioxidant properties of carnosine re-evaluated with oxidizing systems involving iron and copper ions," Basic and Clinical Pharmacology and Toxicology, vol. 96, no. 5, pp. 352-360, 2005.

[124] A. N. Fonteh, R. J. Harrington, A. Tsai, P. Liao, and M. G. Harrington, "Free amino acid and dipeptide changes in the body fluids from Alzheimer's disease subjects," Amino Acids, vol. 32, no. 2, pp. 213-224, 2007.

[125] W. Qi, A. Zhang, T. A. Good, and E. J. Fernandez, "Two disaccharides and trimethylamine $\mathrm{N}$-oxide affect $\mathrm{A} \beta$ aggregation differently, but all attenuate oligomer-induced membrane permeability," Biochemistry, vol. 48, no. 37, pp. 8908-8919, 2009.

[126] D. S. Yang, C. M. Yip, T. H. J. Huang, A. Chakrabartty, and P. E. Fraser, "Manipulating the amyloid- $\beta$ aggregation pathway with chemical chaperones," Journal of Biological Chemistry, vol. 274, no. 46, pp. 32970-32974, 1999. 


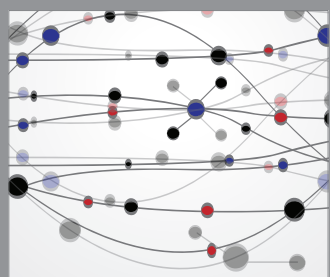

The Scientific World Journal
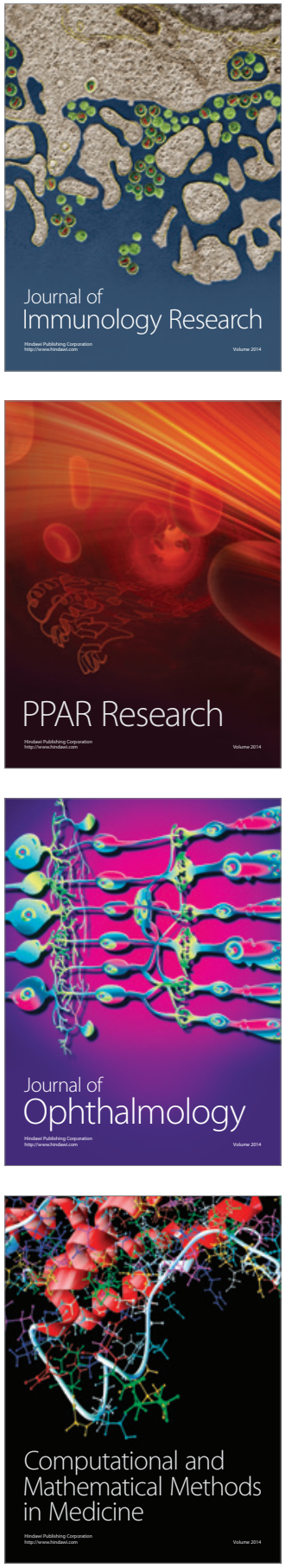

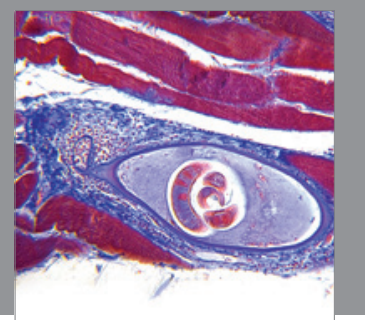

Gastroenterology

Research and Practice
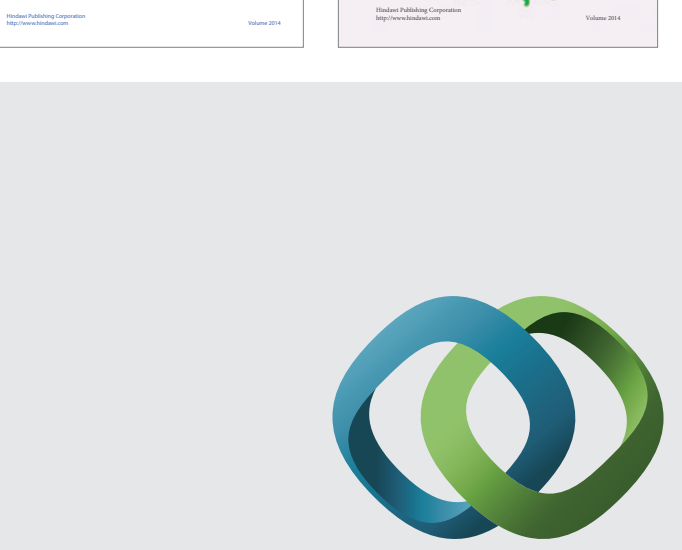

\section{Hindawi}

Submit your manuscripts at

http://www.hindawi.com
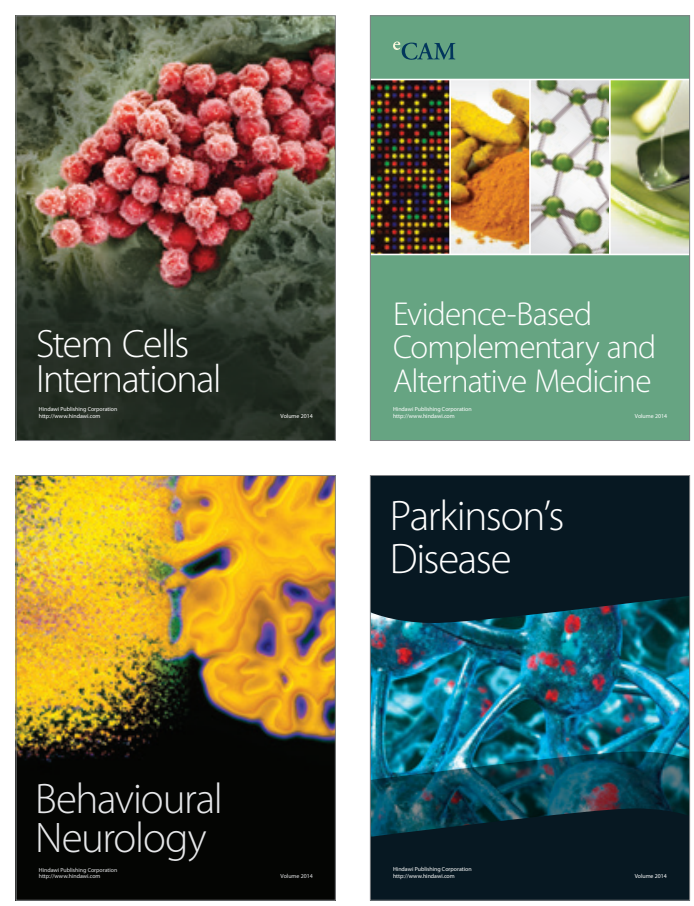

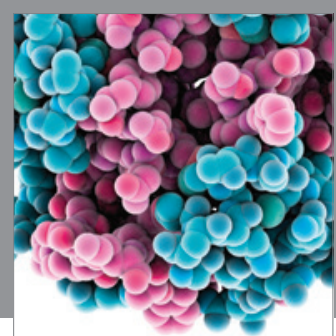

Journal of
Diabetes Research

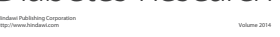

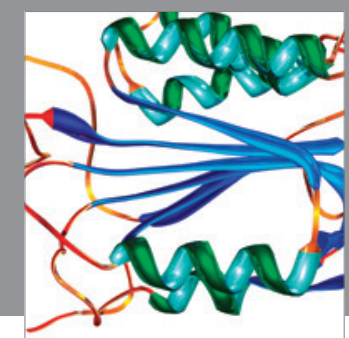

Disease Markers
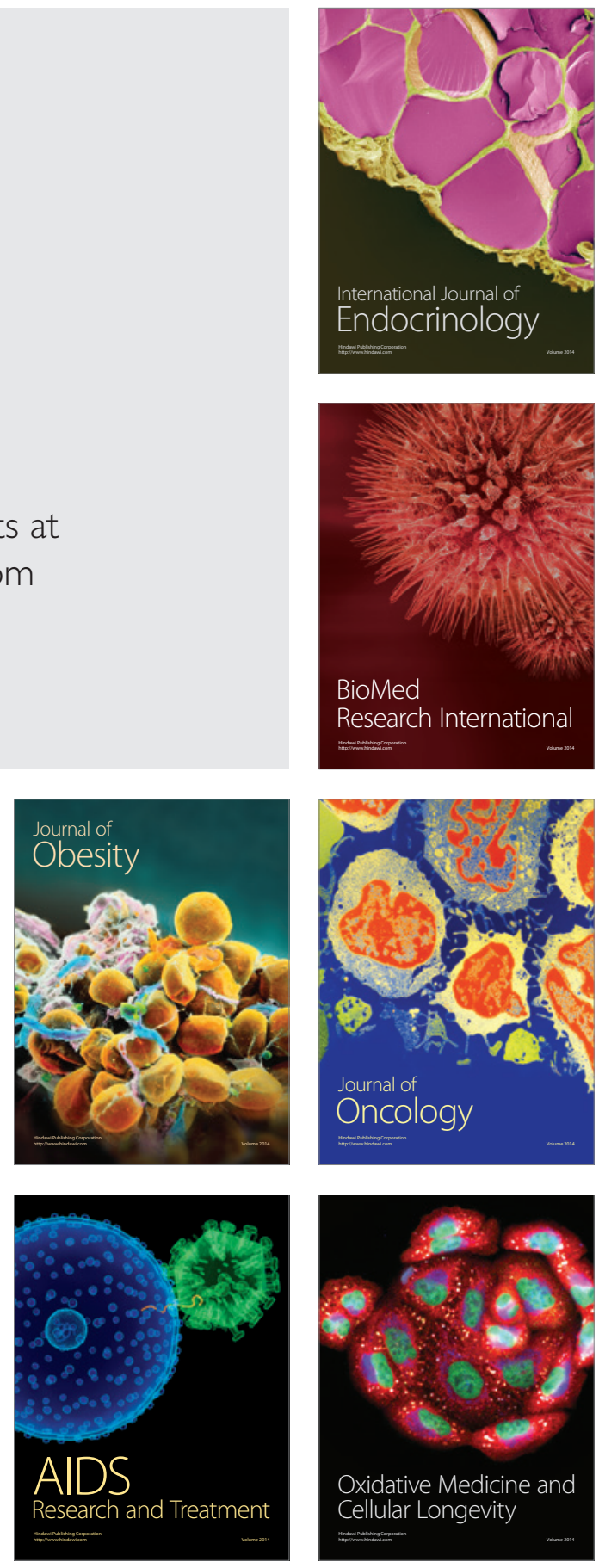